\title{
PLUTONISMO SIN- E TARDI/PÓS-COLISIONAL NO BRASILIANO: EXEMPLO DO MACIÇO LAGOA PRETA (MG/ES):
}

\author{
Valter Salino Vieira ${ }^{1}$, Tania Mara Dussin² \& Adolf Henrich Horn²
}

\begin{abstract}
The Lagoa Preta Massif (Southeast Brazil, Minas Gerais/Espírito Santo), consist of an association of igneous and metaigneous rocks. These magmas intruded gneissic-migmatitic basement during the building of the Neoproterozoic Araçuaí-West Congo Orogen, one of the many Brasiliano/Pan-African orogens that developed during assembly of West Gondwana. The massif is composed of two plutons separated by a directional fault with a N60-70E orientation. Rocks from Northern Pluton are gabbroic cumulates and anorthosites, not deformed nor metamorphosed. The Southern Pluton is constituted by deformed and metamorphosed gabbros, charnockite, diorite and granites. Geological and petrographical data pointed out that the Northern Pluton was emplaced during a late to post-tectonic phase of the Brasiliano Orogeny while the Southern Pluton magmas were emplaced on a syn-tectonic one.
\end{abstract}

\section{Resumo}

\begin{abstract}
O Maciço Lagoa Preta (Sudeste do Brasil, Minas Gerais/Espírito Santo) é uma associação de rochas ígneas e metaígneas. Estes magmas intrudiram o embasamento gnáissico-migmatítico durante a estruturação do Orógeno Araçuaí-Oeste Congo no Neoproterozóico, um dos muitos orógenos Brasiliano/Pan-Africano que se desenvolveram durante a amalgamação do Oeste Gondwana. O Maciço é composto por dois plutons separados por uma falha direcional de orientação N60-70E. Rochas do Pluton Norte são cumulados gabróicos e anortositos

sem deformação ou metamorfismo. O Pluton Sul é constituído por gabros, charnockito, dioritos e granitos deformados e metamorfizados. Dados geológicos e petrográficos indicam que o Pluton Norte foi intrudido numa fase tardi-a pós-tectônica enquanto o Pluton Sul tem características sin-tectônicas.
\end{abstract}

\section{INTRODUÇÃO}

Em torno de 600 Ma atrás, várias seções do antigo continente Rodinia colidiram originando o Orógeno Araçuaí-Oeste Congo, um dos orógenos Brasiliano/ Pan-Africanos que se desenvolveram durante a amalgamação do Oeste Gondwana no final do Proterozóico. O espessamento crustal foi acompanhado por metamorfismo e extensa magmatogênese, com produção de magmas em diferentes fases da evolução tectônica brasiliana (Trompette 1994, 1997; Brito Neves et al. 1999; Almeida et al. 2000; Heilbron et al. 2000, 2004; Pedrosa-Soares \& Wiedemann-Leonardos 2000; Pedrosa-Soares et al. 2001; Alkmin et al. 2006).

Neste trabalho são apresentados dados sobre a geologia e petrografia do Maciço Lagoa Preta, um pluton de estruturação complexa, cuja constituição varia de olivina-gabro a hiperstênio granito, com anortosito associado, que intrudiu gnaisses para- e orto-derivados do embasamento regional durante o Brasiliano. $\mathrm{O}$
Maciço está localizado a oeste da localidade de Vila Nova do Bananal, no limite entre os municípios de Aimorés (MG) e Baixo Guandu (ES) (Figura 1).

Um grande número de estudos tem sido realizado sobre a geologia dos orógenos Araçuaí e Ribeira e sobre o magmatismo brasiliano associado à sua evolução. Estudos sobre a geologia do Maciço Lagoa Preta e da região adjacente foram publicados por Vieira (1997a, 1997b, mas estudos sobre a constituição e natureza da intrusão são escassos. Neste trabalho nós apresentamos dados dos levantamentos de campo de detalhe e semidetalhe do Maciço Lagoa Preta que enfocaram sua estruturação primária, constituição litológica e relações entre os litotipos constituintes, além da deformação e metamorfismo. Os estudos no laboratório constaram de análises petrográficas e de minerais por microscopia ótica convencional e microssonda eletrônica. A íntegra dos resultados analíticos estão em Vieira (1997b). 


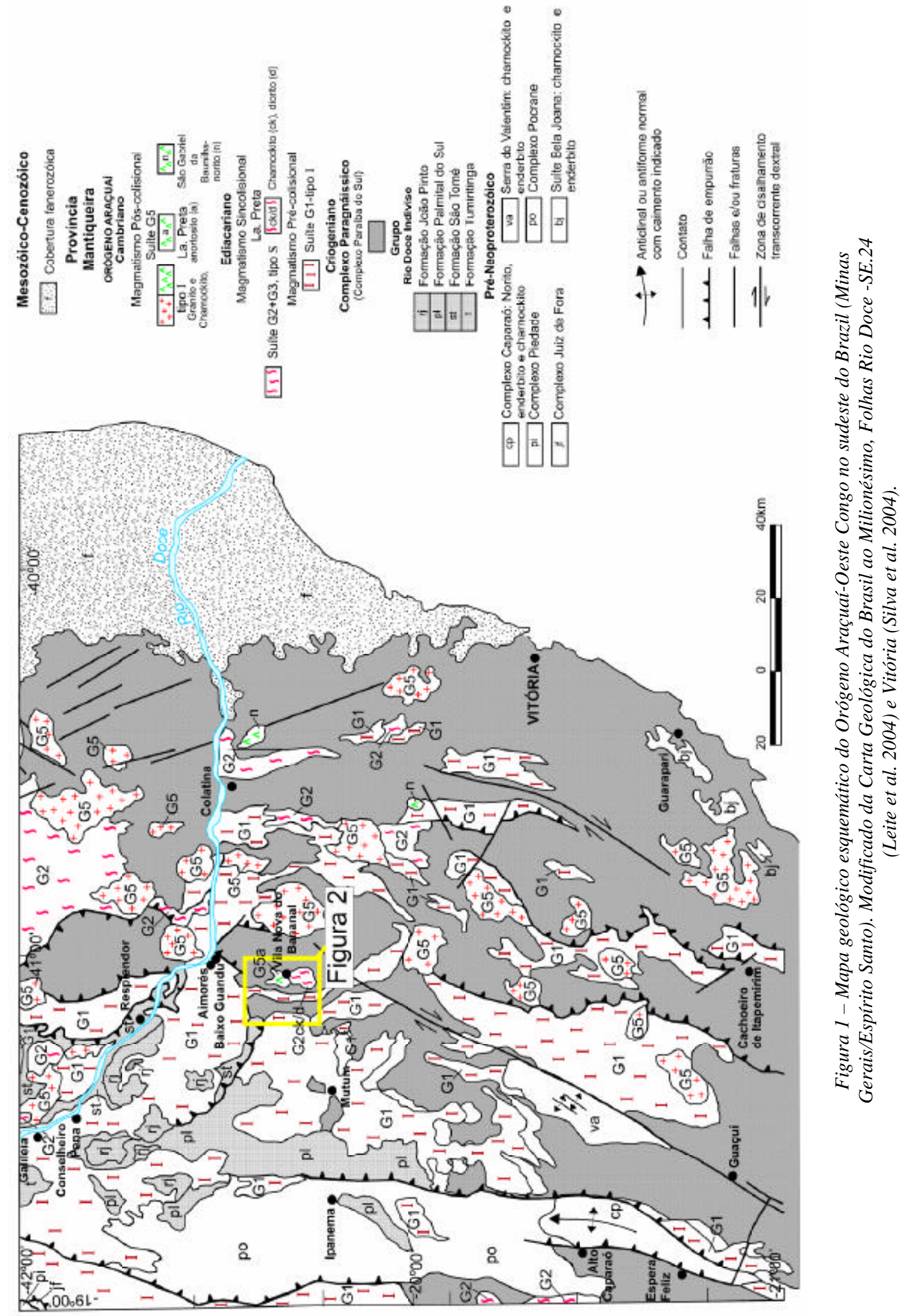




\section{CONTEXTO GEOLÓGICO REGIONAL}

A região do norte do Espírito Santo é dominada por terrenos gnássicos-migmatíticos nos quais ocorrem granulitos, charnockitos e intercalações de metassedimentos. Diferentes complexos metamórficos que estendem-se paralelamente à costa Atlântica têm sido aí individualizados e interpretados como domínios crustais distintos (Wiedemann et al. 1986; Campos Neto \& Figueiredo 1995). O Complexo Paraíba do Sul é um deles. Ele é constituído por gnaisses, migmatitos, quartzitos, quartzo xistos, mármores, rochas calcisilicáticas, e ortognaisses. Dados geocronológicos indicam para os protólitos dos paragnaisses idades variando em torno de $2100 \mathrm{Ma}$ e $770-580 \mathrm{Ma}$ interpretadas como idades máximas e mínimas das fontes sedimentares (U-Pb SHRIMP em zircões detríticos, segundo Noce et al. 2004). Este segmento crustal foi profundamente afetado pela Orogênese Araçuaí-Oeste Congo. Considerável espessamento crustal foi gerado no período em toda a região por dobramentos e falhamentos arranjados num conjunto cinematicamente complexo, com transporte de massas preferencial de leste para oeste nas proximidades do maciço. O metamorfismo associado à fase orogenética principal atingiu as fácies anfibolito e granulito.

Extensa produção de magmas graníticos acompanhou a tectônica e as rochas geradas afloram ao longo de uma faixa que se estende em direção nortesul no interior do Orogéno Araçuaí por cerca de 700 km de extensão e $150 \mathrm{~km}$ de largura (Wiedemann 1993, Noce et al. 2000, Pedrosa-Soares et al. 2001, Wiedemann et al. 2002, De Campos et al. 2004, Heilbron et al. 2004, Martins et al. 2004). Critérios geológicos e geocronológicos levaram ao reconhecimento de fases distintas de geração de magmas: pré-, sin-, tardi- e pós-tectônica (Siga Jr. 1986, Wiedemann 1992, Campos Neto \& Figueiredo 1995). Estes grupos deram origem a cinco fases distintas de geração de magmas referidas como G1 a G5, da mais antiga para a mais jovem (Pedrosa-Soares \& Wiedemann-Leonardos 2000). Segundo estes autores, a Suíte G1 (625-585 Ma), composta por tonalitos e granodioritos com dioritos subordinados, é précolisional e representa fusões relacionadas à subducção num ambiente de arco-margem continental. A Suíte G2 (585-560 Ma) consiste de granitos tipo $\mathrm{S}$ e é considerada como sin-colisional. A Suíte G3 ( 535$510 \mathrm{Ma})$, constituída por leucogranitos peraluminosos, é tardi- a pós-colisional. As suítes G4 e G5 (520-490 Ma) são tardi- a pós-tectônicas e constituídas de granitos tipo $\mathrm{S}$ peraluminosos e granitos tipo I calco-alcalinos, respectivamente.

No Neoproterozóico/Cambriano, um plutonismo granitóide/charnockitóide intrudiu o Complexo Paraíba do Sul sob a forma de batólitos e stocks. A primeira utilização do têrmo Suíte Aimorés para fazer referência às rochas então formadas, foi feita por Silva et al. (1987), que nela incorporou as intrusões de Lagoa Preta e Ibituba as quais englobam rochas anortosíticas, charnockíticas, graníticas e dioríticas. Segundo (Vieira 1997a, 1997b) as intrusões englobadas dentro da Suíte Aimorés têm como características comuns: a) a formação de corpos circunscritos, de forma circular a elíptica, e composição variada (granito, diorito, charnockito, gabro, anortosito); b) apresentam uma assinatura magnética característica: anomalias dipolares de elevado contraste magnético em relação às rochas encaixantes; c) possuem caráter cálcio-alcalino e toleítico; d) são rochas metaluminosas, excepcionalmente, aluminosas; e) identificam-se essencialmente como granitos do tipo I; f) possuem assinaturas tectônicas de arco vulcânico e intraplaca.

\section{O MACIÇO LAGOA PRETA}

\section{Geologia}

O mapa geológico do Maciço Lagoa Preta está representado na Figura. 2. Este mapa corresponde a uma porção da Folha Baixo Guandu (Vieira 1993). Nele foram mantidas as denominações das rochas intrusivas, além das coberturas definidas naquele trabalho. Modificações foram introduzidas principalmente no que se refere a um detalhamento na cartografia dos litotipos já reconhecidos, bem como a individualização de novos.

O Maciço Lagoa Preta intrudiu os terrenos gnáissicos-migmatitíticos do Complexo Paraíba do Sul que constituem o embasamento regional. Rochas encaixantes são orto e paragnaisses aluminosos com granada, biotita e frequentemente cordierita e ou sillimanita. Os gnaisses estão migmatizados em graus diversos e mostram estruturas estromatíticas-flebíticas, nebulíticas e schlieren. Biotita-granada granitos localmente constituem as porções leucossomáticas destas rochas (Rêgo 1989). Intercalações de quartzitos com sillimanita, quartzo xistos, mármores, calcisilicáticas em lentes com espessuras variáveis de decímetros até 50 metros e slices de tremolita-actinolita xistos e anfibolitos são freqüentes. Empurrões NS afetam o complexo gnáissico e estão associados a uma foliação milonítica 115/50 e lineações minerais E/40. Os indicadores cinemáticos, como foliações $\mathrm{S} / \mathrm{C}$ e sombras de pressão em minerais (granada, feldspato) indicam transporte de massas para W. Vieira (1993) reconheceu no embasamento áreas de predomínio de gnaisses aluminosos e áreas com dominância de rochas quartzíticas e calci-silicáticas, utilizando para as últimas a designação de Sequência Sobreiro.

Dados magnetométricos permitiram uma modelagem do complexo até a profundidade de $5 \mathrm{~km}$ indicando que a intrusão é constituída por dois corpos adjacentes que se inclinam em profundidade em direção ao norte (Bosum et al. 1974; Vieira 1993). O corpo norte é constituído por litologias gabróicas com ocorrência de troctolitos e anortositos e tem cerca de 5 $\mathrm{km}^{2}$. Corpos pegmatíticos e aplíticos associados 


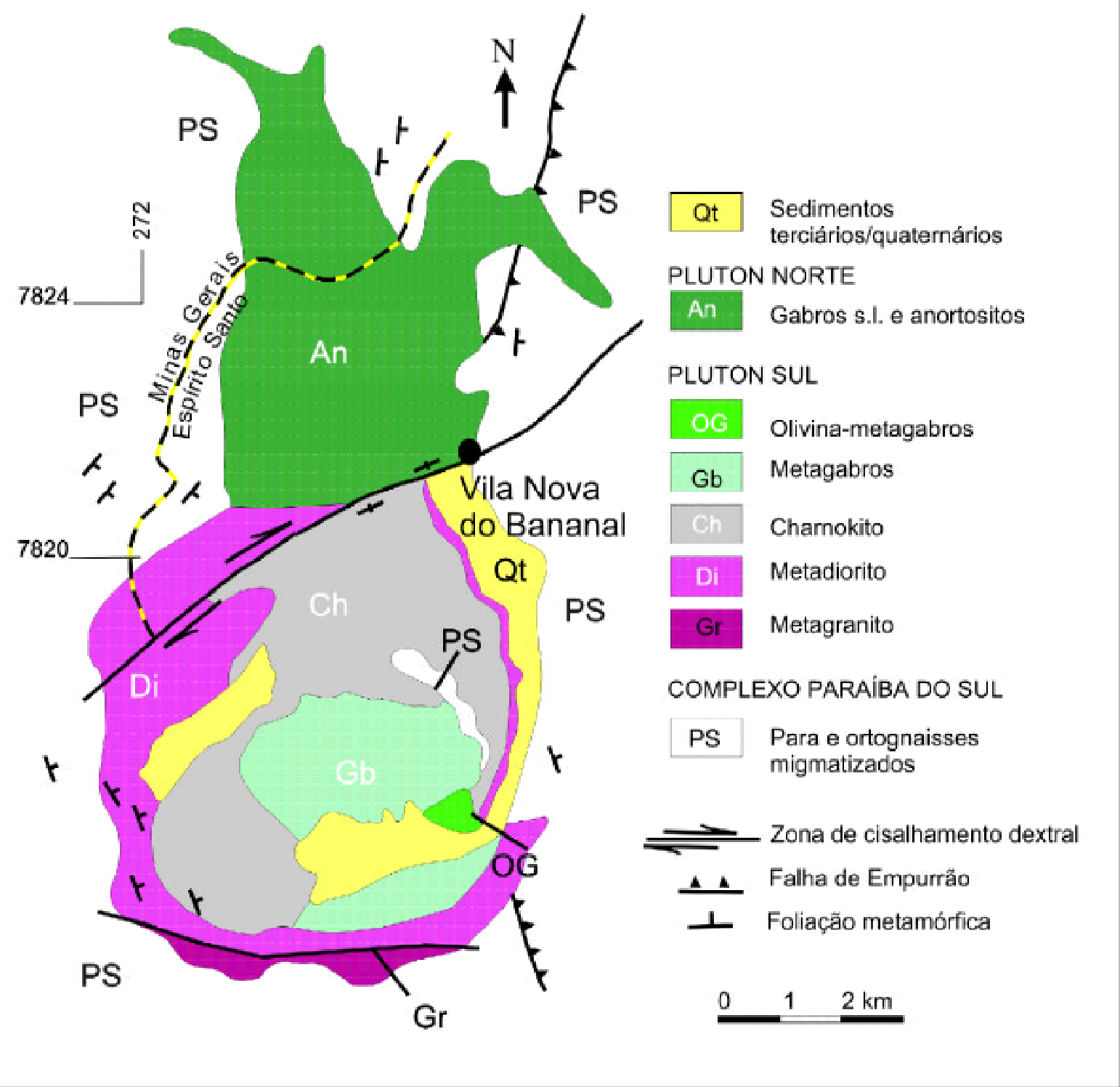

Figura 2 - Mapa geológico do Maciço Lagoa Preta (Minas Gerais/Espírito Santo). Modificado de Vieira (1997b). An =gabros e anortositos, Og=olivina-metagabros, Gb=metagabros, Ch=charnockitos, Di=dioritos, Gt=granitos, $Q t=$ coberturas terciário-quaternárias.

marcam a zona de contato com as encaixantes gnáissicas. O corpo sul é quase circular e tem aproximadamente $20 \mathrm{~km}^{2}$. É constituído por gabros, dioritos, charnockitos (representados por enderbito, charnockito, farsundito) e granito metamorfizado. A intrusão produziu alteração térmica das encaixantes gnáissicas, com formação de cordierita e granada numa zona de contato com espessura superior a 20 metros.

Os dois plutons que constituem o Maciço têm registros de deformação e metamorfismo distintos (Vieira 1993). Os litotipos do Pluton Norte não mostram deformação de caráter penetrativo. As rochas do Pluton Sul são deformadas e metamorfizadas. Uma falha de direcionamento N60-70E, de expressão regional e rejeito principalmente direcional, secciona o Maciço. Esta estrutura afeta rochas dos dois plutons em suas imediações, produzindo o desenvolvimento de uma foliação 330/subvertical e lineações de quartzo 45/40. Estas feições associadas a relações de recristalização mineral, como geometria de sombras de pressão, indicam tratar-se de uma transcorrência dextral.

\section{PETROGRAFIA}

A nomenclatura/classificação das diferentes litologias foram baseadas nas recomendações da IUGS (Le Maître 1989). Desta forma a designação de gabro s.s. foi utilizada para rochas onde o plagioclásio possui An $>50 \%$ e máficos (>10\%) são representados principalmente por olivina e piroxênios. Dioritos são rochas mais ricas em sílica, nas quais plagioclásio apresenta $A n<50 \%$ e máficos (> 10\%) são tipicamente representados por hornblenda e biotita.

\section{Pluton Norte}

É constituído por gabros l.s. Estas rochas ocorrem exclusivamente sob a forma de blocos de escala métrica/ decimétrica que ocorrem em meio a espesso solo de 
alteração de cor avermelhada que recobre grande parte da superfície do terreno. Em alguns blocos pode ser observada uma laminação primária representada por diferentes concentrações de cristais de olivina e espinélio. Sob análise macroscópica, todas as rochas constituintes do Pluton Norte são bastante semelhantes e a distinção entre elas no campo não é possível. Ao microscópio as composições de plagioclásios e minerais máficos, bem como as proporções relativas entre estes dois grupos de minerais permite caracterizar a ocorrência de olivina-gabros e anortositos. Os olivinagabros têm composições normativas com An>50\% e olivina como mineral máfico principal e os anortositos têm anortita variando entre $70-75 \%$ e $90-95 \%$ de plagioclásio modal (Vieira 1977b).

Os gabros l.s. apresentam textura cumulada. $\mathrm{O}$ primeiro mineral a cristalizar é olivina. A cristalização do plagioclásio se segue, e esta fase ocupa todo o espaço livre, sugerindo que a consolidação dos cumulados se deu por crescimento adcumulado (Figura 3 a e b). Em algumas amostras foi observada uma laminação primária representada por assentamento de um maior percentual de olivina e espinélio em determinados níveis. Cristais de olivina mostram formas subédricas a anédricas e são ricos em componente forsterita, o qual varia entre $\mathrm{Fo}_{75-71}$. Estes cristais não estão jamais em contato com plagioclásio: as duas fases são separadas por piroxênios que se formam em torno da olivina e que são, por sua vez, envolvidos por anfibólio em crescimento simplectítico com espinélio. Esta textura é formada por reações de reequilíbrio durante a evolução da cristalização magmática e denominada textura corona (Figura 3c). Plagioclásio é o mineral dominante nos olivina-gabros e anortositos. Possue composições variáveis entre anortita e bytownita $\left(\mathrm{An}_{97-86}\right)$. Os cristais são justapostos formando um mosaico onde as posições intersticiais podem estar ocupadas por olivina ou piroxênio de cristalização precoce. Os cristais de plagioclásio são polissinteticamente maclados e sem zonação composicional detectável ao microscópio. Localmente ocorrem cristais de feldspato deformados. Esta deformação é atectônica como indicado por seu caráter restrito e localizado e foi originada durante o emplacement do pluton. Piroxênios ocorrem sob duas formas: como cristais isolados ocupando porções intersticiais entre cristais de plagioclásio e, principalmente, compondo as coronas. Composicionalmente são ortopiroxênios ricos em enstatita $\left(\mathrm{En}_{77-74}\right)$, que plotam no campo da bronzita. Os cristais são límpidos, sem inclusões ou alteração secundária. Anfibólios ocorrem tanto nas coronas como fora destas. São monoclínicos e de composição magnésio-cummingtonita. Aqueles presentes nas coronas, formam bordas de reação em torno dos piroxênios (Figura 3d). Os cristais aí são de forma vermicular e estão em intercrescimento simplectítico com espinélio. Quando presentes fora da corona, os cristais de anfibólio mostram contornos normalmente anédricos com inclusões de espinélios. Espinélios são de duas gerações distintas: uma primeira está ligada à formação das coronas. Os cristais podem mostrar formas vermiculares, e estão principalmente concentrados na zona externa da corona, próximo aos bordos dos cristais de plagioclásio. Composicionalmente são hercinita. A segunda geração constitui inclusões alinhadas nos cristais de anfibólio, externos à corona. Os cristais apresentam contornos retos e lobados e são picotita e magnetita rica em cromo. Alterações minerais estão representadas pela formação de serpentina e óxido de ferro ao longo dos planos de fratura em olivina e por carbonato e sericita nos plagioclásios. Estas alterações são possivelmente relacionadas a reações de reequilíbrio numa fase magmática tardia. Não há registros de metamorfismo e nem deformação penetrativa nestas rochas.

\section{Pluton Sul}

O Pluton Sul mostra uma estrutura inversamente zonada com metagabros e olivina-metagabros constituindo sua porção central, a qual é envolvida por charnockito. A porção mais externa do pluton é constituída por rochas dioríticas e graníticas metamorfizadas. Existe uma foliação reconhecível localmente em todas as rochas compondo o pluton que é discordante da foliação regional. Esta foliação, resultante do fluxo magmático, é definida pela orientação dos eixos maiores de biotitas e prismas de anfibólios e tem direções variadas e mergulhos preferenciais dirigidos para o centro do corpo.

De forma distinta do Pluton Norte, as litologias do Pluton Sul são tectonicamente deformadas. Uma foliação cataclástica com orientação 120/30 sobrepõese à foliação magmática. Ela é definida pela alternância de zonas onde existe claro predomínio da cominuição sôbre a recristalização mineral e zonas com texturas ígneas preservadas. As zonas cisalhadas veicularam a circulação de fluidos metamórficos ricos em Si e K que produziram alteração hidrotermal de minerais primários numa fase tardia da evolução tectônica, com formação de uma mesóstase muito fina de composição quartzofeldspática. Existem também substituições da clinoferrosilita por grunerita nos charnockitos, de biotita por clorita nos gabros e serpentinização da olivina nos olivina-metagabros.

\section{Olivina-metagabros}

Um pequeno corpo de olivina-metagabro ocorre na parte central do pluton. Os afloramentos são restritos e muito alterados e no campo a distinção do gabro, que o envolve, se dá pela coloração do solo, de um avermelhado menos intenso no caso destes últimos. Em afloramentos o olivina-gabro acha-se cortado por veios pegmatíticos e aplíticos deformados, de constituição quartzo-feldspática e ligados ao charnockito que envolve o núcleo máfico do pluton. Ao microscópio observa-se nestas rochas textura ígnea preservada, do tipo granular, localmente de caráter cumulado, em faixas de espessuras milimétricas que alternam com outras nas quais ocorrem texturas do tipo cataclástica, 
com minerais cominuídos predominando sobre aqueles recristalizados. Minerais essenciais dos olivinametagabros são plagioclásio (50\%), olivina (20\%), hornblenda $(15 \%)$, diopsídio $(5 \%)$ e quartzo $(5 \%)$. Minerais acessórios estão representados por zircão e opacos. Nas porções em que a textura ígnea está preservada, plagioclásio apresenta formas euédricas a subédricas com deformação das maclas polissintéticas. Olivina não está jamais em contato com o plagioclásio. Estas duas fases são separadas por coronas de reação representadas por piroxênio, mais internamente, e por anfibólio em crescimento simplectítico com espinélio, nos contatos com o plagioclásio, num arranjo textural igual ao mostrado pelas rochas gabróicas do Pluton Norte (Figura 4a e b). Piroxênios ocorrem exclusivamente compondo as coronas em cristais límpidos e sem inclusões. Anfibólios ocorrem nas coronas, como produto de reações de reequilíbrio mineral, ou como cristais isolados fora das coronas. Nas faixas deformadas, cristais de plagioclásio estão cominuídos e mostram recristalização nas bordas para albita. Anfibólios mostram orientação preferencial e quartzo, com ocorrência restrita às faixas deformadas, acha-se estirado e com forte extinção ondulante. São características em toda a rocha serpentinização da olivina, uralitização do piroxênio, cloritização do anfibólio e albitização, sericitização e saussuritização do plagioclásio.

\section{Metagabros}

Macroscopicamente são rochas de grão médio a grosso, estrutura maciça e cor esverdeada. Os afloramentos são arrasados pelo intemperismo e a ocorrência deste litotipo é restrita a blocos de variados tamanhos. Quando intemperizadas estas rochas adquirem uma coloração cinza esbranquiçada com pontos esverdeados e amarelados (resultantes da alteração de piroxênios e anfibólio), assumindo um aspecto característico. Ao microscópio são foliadas e mostram alternância de faixas não deformadas, nas quais a textura ígnea é preservada, com faixas deformadas nas quais predominam texturas cataclásticas (Figura 4c). Minerais essenciais são labradorita (45\%), diopsídio (30\%), hornblenda (10\%), opacos (10\%) e quartzo (5\%). Plagioclásio é labradorita com bordas albitizadas. Piroxênio é representado por diopsídio, que ocorre em cristais anédricos, fraturados e dispostos segundo a foliação cataclástica. O anfibólio é hornblenda de coloração esverdeada. Quartzo acha-se fraturado, disposto segundo a foliação cataclástica e com forte extinção ondulante. Minerais acessórios são monazita, apatita e opacos. Outras alterações minerais observadas são uralitização do piroxênio e cloritização do anfibólio.

\section{Charnockito}

Macroscopicamente é uma rocha bastante uniforme, homogênea sem qualquer estruturação visível, de grão grosso e cor esverdeada em superfícies frescas, ou amarronzada quando parcialmente intemperizada.
Localmente são observados xenólitos centimétricos de composição máfica. Ao microscópio apresenta textura porfirítica com fenocristais de feldspato imersos numa matriz representada por minerais máficos e quartzo. Em determinadas porções, entretanto, a textura é claramente cataclástica. A paragênese original mostra-se nestes locais, cominuída e recristalizada numa mesóstase muito fina de composição quartzo-feldspática (figura 4d). Minerais essenciais são ortoclásio (45\%), plagioclásio (25\%), piroxênio (15), anfibólio (10\%) e quartzo (5\%). Ortoclásio é o mineral mais abundante, ocorrendo na forma de pertita do tipo string. São fenocristais subédricos, maclados segundo Carlsbad. Apresentam extinção ondulante e fraturas preenchidas por hidróxido de ferro e sericita. Plagioclásio ocorre em cristais límpidos, subédricos, com macla albitaCarsbad, localmente recurvadas. São oligoclásio/ andesina com composição $\left(\mathrm{Ab}_{70-68}\right)$. Nos contatos do plagioclásio com o ortoclásio ocorre desenvolvimento de mirmequitas. Piroxênio é de dois tipos. O primeiro tipo é um ortopiroxênio de composição clinoferrosilita $\left(\mathrm{Fs}_{84-78}\right)$. Ocorre em cristais subédricos, fraturados e localmente como inclusões nos piroxênios do segundo tipo. Mostra alteração local para grunerita. O segundo é clinopiroxênio da série diopsídio-augita, possuindo formas anédricas. Anfibólio é representado por grunerita e geralmente observado como coroas reacionais em torno do piroxênio. Quartzo está representado principalmente na mesóstase quartzofeldspática e mostra extinção ondulante. Minerais acessórios são zircão, titanita, opacos e apatita. Alterações de reequilíbrio mineral são sericitização do feldspato e cloritização de anfibólio.

\section{Metadiorito}

Possui coloração verde-escura, granulação fina a média e uma conspícua orientação mineral. As relações de contato com as encaixantes são de difícil observação devido à formação de espesso manto de alteração intempérica. Minerais essenciais destas rochas são plagioclásio (30-50\%), piroxênio (5-25\%), biotita (20$25 \%$ ), anfibólio (10\%), granada (20\%) e quartzo (5\%). Minerais acessórios são opacos, apatita e zircão. Ao microscópio a textura é essencialmente granoblástica (Figura 4e) e a foliação, onde visível, definida pela orientação de biotita. Plagioclásio é andesina $\left(\mathrm{An}_{38-34}\right)$. que ocorre frequentemente em cristais com zonação composicional normal e deformação das maclas polissintéticas. Piroxênio é clinoferrosilita. Ocorre de forma intergranular com o plagioclásio e sua abundância está em relação inversa à quantidade de quartzo presente na rocha. Biotita ocorre em cristais orientados que definem a foliação da rocha e são localmente englobados por granada. Anfibólio é hornblenda que ocorre como cristais bem desenvolvidos de forma subédrica/anédrica. Granada ocorre como cristais poiquiloblásticos com inclusões de biotita e quartzo ou como agregados de cristais de pequeno tamanho. Quartzo ocorre preferencialmente em níveis submilimétricos, orientados segundo a foliação da 
rocha. Ao microscópio apresentam formas anédricas e microinclusões de granada. Alterações minerais observadas são sericitização e saussuritização do plagioclásio, uralitização do piroxênio, cloritização do anfibólio e da granada.

\section{Metagranito}

Tem coloração acinzentada e granulação média a grossa. Análises microscópicas indicam microclina (35\%), plagioclásio $(40 \%)$, quartzo $(20 \%)$ e biotita $(5 \%)$. Mostram textura porfiroclástica com grandes cristais de microclínio e plagioclásio ocelares $(\sim 3,0 \mathrm{~cm})$ numa matriz de composição quartzo-feldspática na qual os minerais recristalizados têm orientação preferencial que define, junto com biotita a foliação da rocha (Figura 4f). Localmente, a recristalização do quartzo define lineações. Minerais acessórios estão representados por zircão e apatita. Processos de alteração mineral estão representados por sericitização do plagioclásio e cloritização da biotita.

\section{CONSIDERAÇÕES SOBRE EVOLUÇÃO GEOLÓGICA E PETROGÊNESE DO MACIÇO}

Em sítios de convergência de placas o aumento de $\mathrm{P}$ e $\mathrm{T}$, na presença de fluidos, gera magmas com composições distintas, as quais são influenciadas por variáveis potencialmente independentes como a composição da fonte magmática e os parâmetros físicoquímicos relativos ao processo de fusão. Além disto, o magma ascendente, ou durante a cristalização na câmara magmática, pode interagir com a litosfera em graus variáveis e a extensão desta interação dependerá da duração do processo, da composição da litosfera e do gradiente de temperatura entre a intrusão e as encaixantes. A conseqüência de tal modelo multiestágio, multi-componente e multi-processos é uma grande diversidade de magmas de diferentes composições numa mesma área. Nas margens convergentes, magmas primitivos têm sido descritos em um pequeno número de arcos vulcânicos e rochas basálticas, andesíticas e ácidas com alto-Al são absolutamente dominantes.

No Maciço Lagoa Preta, rochas oriundas de magmas de composição primária não foram reconhecidas. As rochas formadas pela cristalização dos magma mais primitivos reconhecidos no Maciço são os gabros 1.s. do Pluton Norte. As feições petrográficas das amostras em lâminas indicam que a cristalização magmática evoluiu por um processo de diferenciação onde o assentamento de cristais teve papel dominante. Fusões residuais, após a cristalização dos gabros, possivelmente deram origem aos pegmatitos e aplitos que ocorrem em associação com o Pluton em sua porção norte. $\mathrm{O}$ lento resfriamento do magma levou à formação de bordas de reação entre cristais primários (textura

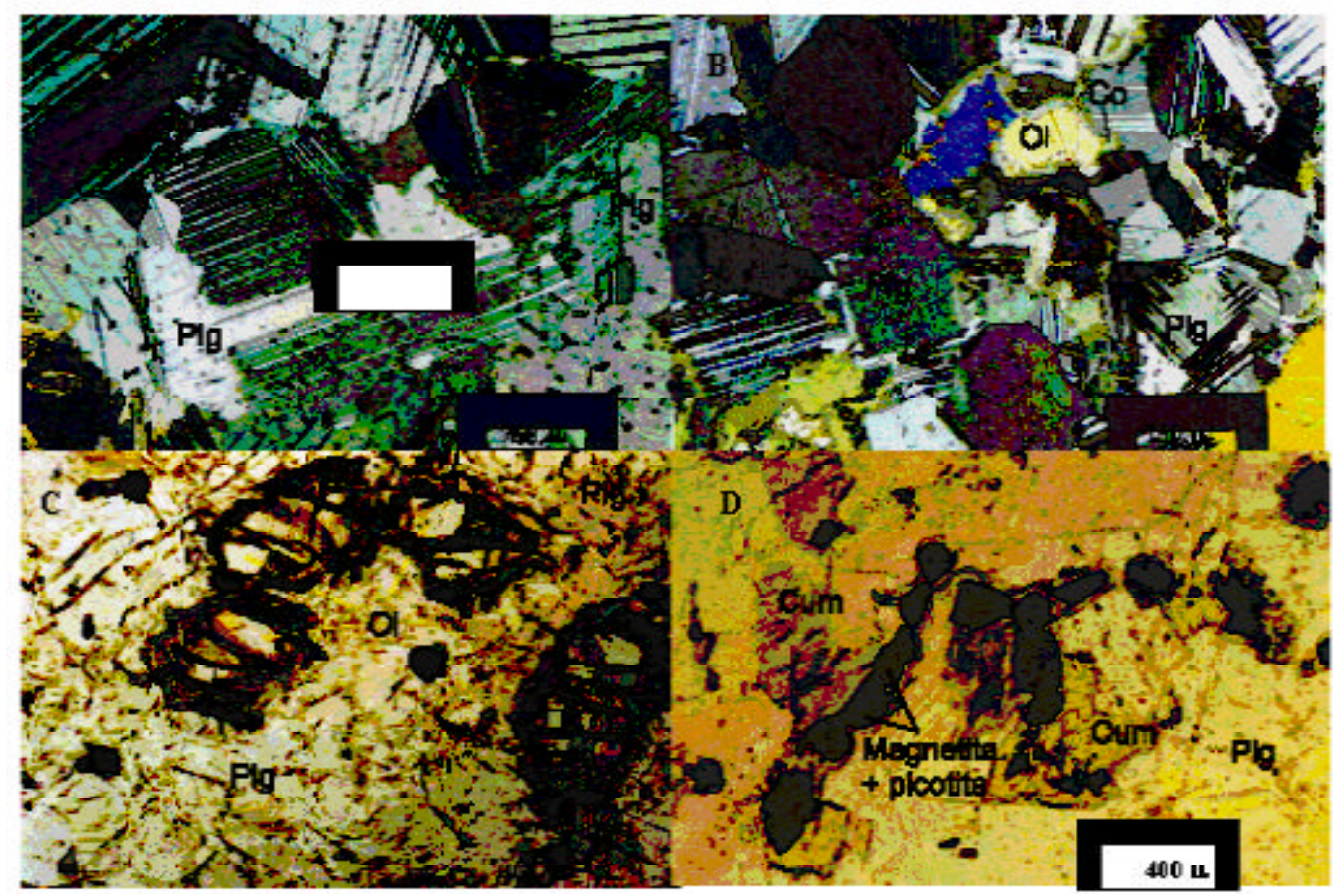

Figura 3. Fotomicrografias de rochas gabróicas do Pluton Norte. (a). Textura adcumulática em anortosito. (Nicóis \#) (b). Textura adcumulática em anortosito. Os cristais de olivina não estão jamais em contato direto com o plagioclásio e são separados deste por zonas de alteração resultantes de reações de reequilíbrio mineral constituídas essencialmente por piroxênios e anfibólios. (Nicóis \#.) (c) Detalhe de olivina com textura corona em anortosito. ( Nicóis //) (d) Detalhe de magnésio-cummingtonita externa à corona mostrando inclusões de picotita e magnetita rica em cromo. (Nicóis //) Ol=olivina, Co=corona, Cum=magnesio-cummingtonita, Gru=grunerita, Dp/aug=diosídio-augita, Plg=plagioclásio. 


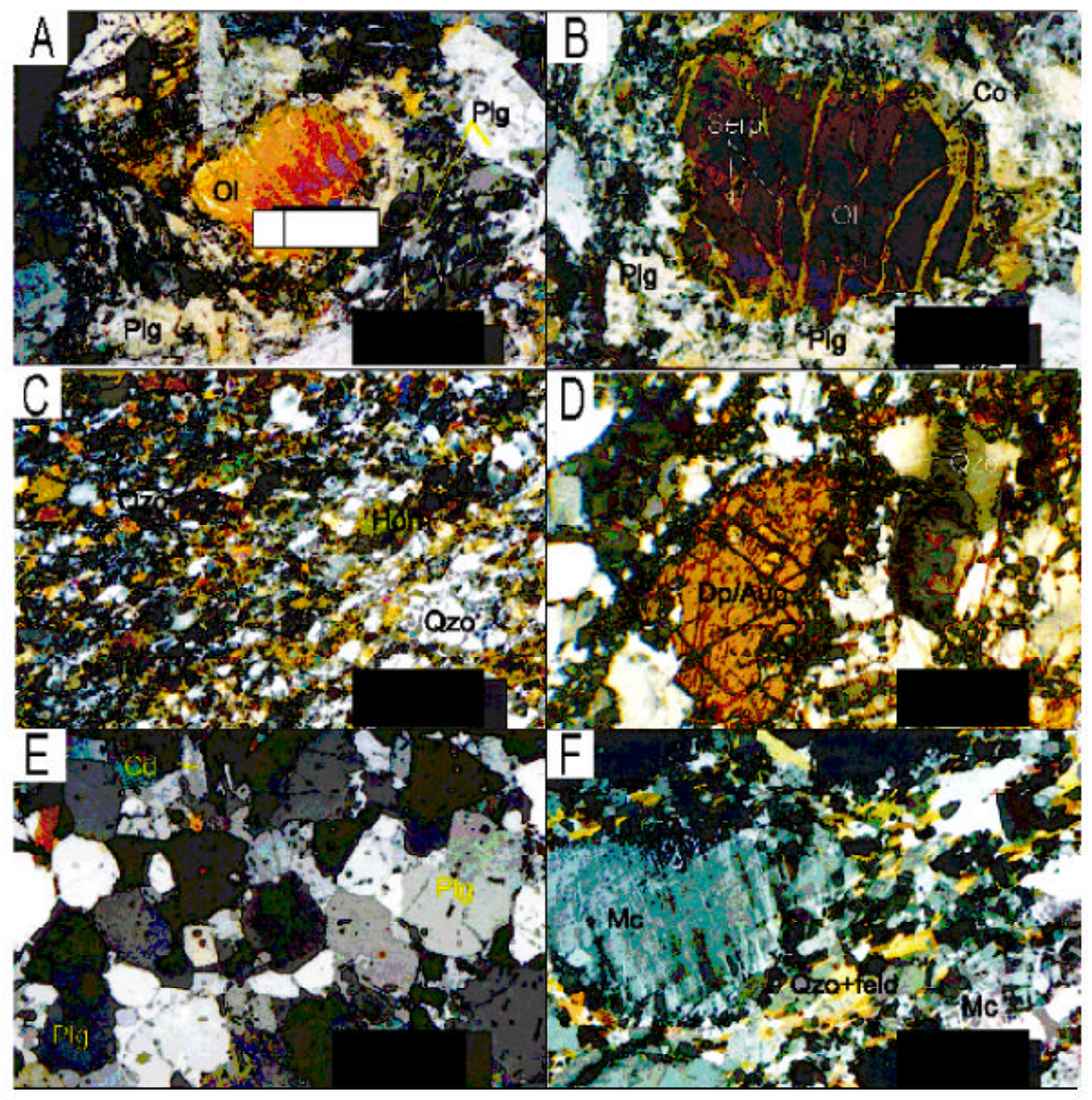

Figura 4. Fotomicrografias de rochas do Pluton Sul. (a) Olivina-metagabro com cristal de olivina circundado por plagioclásios deformados. Ao longo dos planos de fraturas do cristal de olivina ocorre serpentina. (Nicóis \#) b) Detalhe do cristal de olivina da foto anterior, mostrando a formação de corona nos contatos com plagioclásio. (Nicóis \#) c) Textura cataclástica em metagabro (Nicóis \#) (d) Textura característica dos charnockitos com diopsídio-augita envolvido por quartzo e feldspato potássico cominuídos e parcialmente recristalizados. (Nicóis \#) (e) Metadiorito em zona de contato com encaixante gnáissica. (Nicóis \#).f) Granito com textura cataclástica mostrando cominuição do quartzo e feldspato. Na porção superior do cristal de microclínio ocorre mirmequita. (Nicóis \#) Ol=olivina, Co=corona, Dp/aug=diopsídio, Horn=honblenda, $P l g=$ plagioclásio, $M c=$ microclínio, Qzo= quartzo, Serp=serpentina, Cd=cordierita.

corona). Condições nas quais a cristalização magmática ocorreu podem ser inferidas pela presença de espinélio nos simplectitos dos gabros do Maciço Lagoa Preta, a qual é sugestiva de temperaturas mais altas e pressões mais baixas do que aquelas necessárias para estabilidade da granada.

Comparativamente ao Pluton Norte, as rochas constituintes do Pluton Sul indicam derivação a partir de magmas de características mais evoluídas com uma composição marcadamente mais aluminosa e com menores concentrações de Mg. Estas características são sugestivas de formação de magmas nos quais a participação da crosta é relativamente mais importante. As relações de campo entre os diferentes litotipos constituintes do Pluton Sul sugerem que a complexa estruturação do pluton em zonas concêntricas de diferentes composições, é o resultado de sucessivos pulsos na câmara magmática durante a cristalização. Esta interpretação tem como base a ocorrência de veios pegmatíticos e aplíticos de composição charnockítica cortando o olivina-gabro e a ocorrência de xenólitos do gabro no charnockito. Segundo Vieira (1997b), as 
feições geoquímicas do Pluton Sul indicam que um magma único de natureza crustal se diferenciando originou todos os tipos litológicos constituintes do Pluton.

Os dados geológicos disponíveis para o Maciço Lagoa Preta indicam que os plutons Norte e Sul foram intrudidos em momentos distintos relativamente à principal fase orogênica brasiliana. Este fato fica evidente pelo contraste entre a deformação e o metamorfismo dos dois plutons. O Pluton Sul mostra foliação concordante com a estruturação das encaixantes: uma foliação $120 / 30$ marcada por orientação mineral preferencial de biotita e hornblenda e metamorfismo da fácies xisto verde. Resultados geocronológicos disponíveis para o charnockito indicam para este Pluton idades de cristalização de 585 $\mathrm{Ma}(\mathrm{Pb} / \mathrm{Pb}$ em zircões, Dussin et al. 1998). Estes dados, em consonância com os dados geológicos e geocronológicos regionais, indicam para o Pluton Sul um caráter sin-colisional. A intrusão do magma que originou o Pluton Norte, por outro lado, é certamente posterior à intrusão do Pluton Sul e, portanto, ao estágio colisional. Esta idéia é suportada pela ausência de deformação e metamorfismo nestas rochas, em nítido contraste com as características do Pluton Sul. É possível que este episódio tenha ocorrido já em contexto extensional, o qual caracteriza os estágios orogenéticos finais. Tal contexto pode ter facilitado uma subida relativamente rápida do magma, diminuindo as possibilidades de interação com as encaixantes e permitindo que ele guardasse um caráter mais primitivo.

A falha direcional de orientação N60-70E que corta o maciço, afeta litotipos dos plutons Norte e Sul. Esta estrutura está possivelmente ligada aos estágios finais da tectônica brasiliana e relacionada à expansão das áreas orogênicas em direção a sul. Esta expansão está registrada pelos sistemas de transcorrências dextrais do leste de Minas Gerais e Espírito Santo, cujo prolongamento sul constitui a própria faixa Ribeira. (Alkmin et al. 2003).

\section{AGRADECIMENTOS}

Á CPRM - Serviço Geológico do Brasil, por todo o apoio financeiro aos trabalhos de campo e de laboratório, e ao CPMTC/IGC/UFMG pela infraestrutura e apoio laboratorial. Aos revisores pelas sugestões ao manuscrito.

\section{REFERÊNCIAS}

Alkmin, F.F., Marshak, S., Pedrosa-Soares, A.C., Peres, G.G., Cruz, S.C.P., Whittington, A. 2006. Kinematic evolution of the AraçuaíWest Congo orogen in Brazil and Africa: nutcracker tectonics during the Neoproterozoic assembly of Gondwana. Precambrian Res. 149, 43-64.

Alkmin, F.F., Marshak, S., Pedrosa-Soares, A.C., Peres, G.G., Cruz, S.C.P., Whittington, A. 2003. Tectônica quebra-nozes e a gênese do Orógeno Araçuaí-Congo Ocidental. In: Simpósio Nacional de Estudos Tectônicos, Búzios. Bol. Res. Exp., p. 40-45.

Almeida, F.F.M., Brito Neves, B.B., Carneiro, C.D.R. 2000. Origin and evolution of the South American platform.
Earth Sci. Rev. 50, 77-111.

Bosum, W., Hagen, D., Mollat, H. 1974. Relatório de reconhecimento geológico-geoquímico Guandu-Castelo, Minas Gerais-Espírito Santo. Relatório Inédito DNPM/CGBA, 52p.

Brito Neves, B.B., Campos Neto, M.C, Fuck, R. 1999. From Rodínia to Western Gondwana: an approach to the Brasiliano/Pan-African Cycle and orogenic collage. Episodes 22, 155-199.

Campos Neto, M.C., Figueiredo, M.C. 1995. The Rio Doce Orogeny, South-Eastern Brazil. J. South Am. Earth Sci., 8:143-162.

De Campos, C., Mendes, J., Ludka, I., de Medeiros, S., de Moura, J., Wallfass, C. 2004. A review of the Brasiliano magmatism in southern Espírito Santo, Brazil, with emphasis on post-collisional magmatism. In: (eds.) Weinberg, R., Trouw, R., Fuck, R., and Hackspacher, P., The 750-550 Ma Brasiliano Event of South America, J. Virtual Explorer, Electronic Edition, ISSN 14418142, Volume 17, Paper 1.

Dussin, I. A ., Dussin, T. M., Vieira, V. S.; Macambira, M. J.B. 1998. Idade do Maciço Lagoa Preta (Suíte Aimorés, MG/ES): Determinação de $207 \mathrm{~Pb} / 206 \mathrm{~Pb}$ sobre zircões de Hiperstênio Granito. In: Congr. Bras. Geol., Belo Horizonte, Anais...40, p.34.

Heilbron M., Pedrosa-Soares, A.C., Campos Neto, M., Silva, L.C. da; Trouw, R., Janasi, V. 2004. A Província Mantiqueira. In: MantessoNeto, A., Bartorelli, C.D.R.,.Brito Neves, B.B. (eds.) Geologia do Continente Sul-Americano: Evolução da obra de Fernando Flávio Marques de Almeida. Beca Prod. Cult. Ltda, p.17-35.

Heilbron, M., Pedrosa-Soares, A.C., Neto, M., Silva, L., Trouw, R., Janasi, V. 2004. Brasiliano orogens in Southeast and South Brazil. In: Wienberg, R., Trouw, R., Hackspacher, P. (Eds). The 750550 Ma Brasiliano Event of South America. J. Virtual Explorer. Electronic edition 17, Paper 4.

Le Maître, R.W. 1989. A classification of igneous rocks and glossary of terms. Oxford: Black Well Scientific Publ. Cap. B, pp.03-34.

Leite, C.A.S., Souza, J.D., Silva, S.L., Kosin, M., Silva, L.C., Bento, R.V., Santos, R.A., Vieira, V.S., Camozzato, E., Paes, V.J.C., Neto, C., Junqueira, P.A. 2004. Folha SE.24-Rio Doce. In: Schobbenhaus, C., Gonçalves, J.H., Santos, J.O.S., Abram, M.B., Leão Neto, R., Matos, G.M.M., Vidotti, R.M., Ramos, M.A.B., Jesus, J.D.A.de., (eds.). Carta Geológica do Brasil ao Milionésimo, Sistema de Informações Geográficas. Programa Geologia do Brasil, CPRM, Brasília.

Martins, V.T.S., Teixeira, W., Noce, C.M., Pedrosa-Soares, A.C. 2004. $\mathrm{Sm}$ and $\mathrm{Nd}$ characteristics of Brasiliano/Pan-African granitoid plutons of the Araçuaí Orogen Southeastern Brazil: Tectonic implications. Gondwana Res. 7(1), 75-89.

Noce, C.M., Macambira, M.B., Pedrosa-Soares, A.C. 2000. Chronology of Neoproterozoic-Cambrian granitic magmatism in the Araçuaí Belt, Eastern Brazil, based on single zircon evaporation dating. Rev. Bras Geol., 30 (1), 25-29.

Noce, C.M., Pedrosa-Soares, A.C., Piuzana, D., Armstrong, R., Laux, J.H., Campos, C., Medeiros, S.R. 2004. Ages of sedimentation of the kinzigitic complex and of a late orogenic thermal episode in the Araçuaí Orogen, northern Espírito Santo State, Brazil: zircon and monazite U-Pb SHRIMP amd ID-TIMS data. Rev. Bras Geol., 349 (4), 587-592.

Pedrosa-Soares, A.C., Wiedemann-Leonardos, C.M. 2000. Evolution of the Araçuaí Belt and its connection to the Ribeira Belt, Eastern Brazil. In: Cordani, U.G., Milani, E.J.; Thomaz Filho, A.; Campos, D.A. (eds) Tectonic evolution of South America. Rio de Janeiro, p.: 265-285.

Pedrosa-Soares, A.C., Noce, C.M., Wiedemann, C., Pinto, C.P. 2001. The Araçuaí-West-Congo Orogen in Brazil: An overview of a confined orogen formed during Gondwanaland assembly. Precambrian Res. 110 (1-4): 307-323.

Rego, I.T.S.F. 1989. Petrologia e geoquímica da unidade charnockítica Bela Joana, região de São Fidélis, RJ. Universidade de São Paulo, 349p. (Tese inédita)

Siga Jr., O. 1986. A evolução geotectônica da porção nordeste de Minas Gerais com base em interpretações geocronológicas. Univ. São Paulo, São Paulo, 140 p. (Tese inédita)

Silva, M.A., Camozzato, E., Paes, V.J.C., Junqueira, P.A., Rangrab, G.E. 2004. Folha SF.24-Vitória. In: Schobbenhaus, C., Gonçalves, J.H., Santos, J.O.S., Abram, M.B., Leão Neto, R., Matos, G.M.M., Vidotti, R.M., Ramos, M.A.B., Jesus, J.D.A.de., (eds.). Carta Geológica do Brasil ao Milionésimo, Sistema de Informações Geográficas. Programa Geologia do 
Brasil. CPRM, Brasília.

Silva, J.M.R., Lima, M.I.C., Veronese, V.F., Ribeiro, Jr., R.N., Rocha, M.R., Siga Jr., O. 1987. Geologia. In: Projeto RADAMBRASIL, Levantamento de Recursos Naturais. Folha SE.24 - Rio Doce. Rio de Janeiro, v. 34, 548p.

Trompette, R., 1994. Geology of Western Gondwana (2000-500 Ma) In: Pan-African/Brasiliano aggregation of south America and Africa. A.A. Balkema, Rotterdam, 350p.

Trompette, R., 1997. Neoproterozoic ( 600Ma) aggregation of Western Gondwana: a tentative scenario. Precambrian Res. 82, 101-112.

Vieira, V. S. 1997a. Projeto Mapeamento Geológico/Metalogenético Sistemáticos: Programa Levantamentos Geológicos Básicos do Brasil. Folha Cachoeiro de Itapemirim - SF.24-Z-V-A, Escala 1:250.000. Brasília: DNPM/CPRM, 99p., v. 1 (Inédito).

Vieira, V.S. 1993. Programa de levantamentos geológicos básicos do Brasil; Projeto Cachoeiro de Itapemirim. Carta Geológica, Carta Metalogenética/Previsional, Folha Baixo Guandu, SE.24Y-C-V, Escala 1:100.000, Estado de Minas Gerais / Espírito Santo. Brasília, DNPM/CPRM, (Relatório Final), 175 p.
Vieira, V.S.1997b. Geoquímica do Maciço Lagoa Preta, MG/ES: Exemplo de plutonismo em domínio de arco magmático. Dissertação de Mestrado. Instituto de Geociências, Universidade Federal de Minas Gerais, $87 \mathrm{p}$.

Wiedemann, C. 1993. The evolution of the early Paleozoic, late to post-collisional magmatic arc of the Coastal Mobile Belt in the State of the Espírito Santo, Eastern Brazil. An. Acad. Bras. Sci. 65(1): 163-181.

Wiedemann, C. M. 1992. Evolução magmática brasiliana do Cinturão Móvel Ribeira no estado do Espírito Santo. In: Congr. Bras. Geol., 37, São Paulo. Bol. Res .Exp., p. 40-45.

Wiedemann, C., Bayer P., Horn H., Lammerer B., Ludka I.P., SchmidtThome R., Weber-Diefenbach K. 1986. Maciços Intrusivos do Sul do Espírito Santo e seu Contexto Regional. Rev. Bras. Geoc., 16:24-37.

Wiedemann, C., Medeiros, S.R., Ludka, I.P., Mendes, J.C., Moura, J.C., Costa Nascimento, R.C. 2002. Architecture of late orogenic plutons in the Araçuaí-ribeira Folf belt, Southeast Brazil. Gondwana Res. 5:381-399. 